\title{
Spinning, drawing and physical properties of polypropylene nanocomposite fibers with fumed nanosilica
}

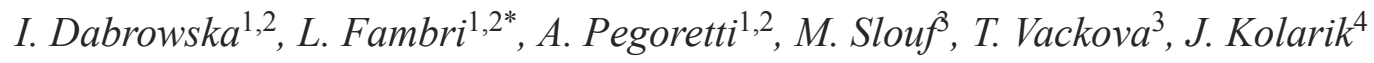 \\ ${ }^{1}$ Department of Industrial Engineering, University of Trento, via Sommarive 9, 38123 Trento, Italy \\ ${ }^{2}$ National Interuniversity Consortium for Science and Technology of Materials (INSTM), Via G. Giusti 9, 50121 Firenze, \\ Italy \\ ${ }^{3}$ Institute of Macromolecular Chemistry, Academy of Sciences of the Czech Republic, Heyrovsky Sq. 2, 16206 Prague 6, \\ Czech Republic \\ ${ }^{4}$ Visiting professor, Department of Industrial Engineering, University of Trento, via Sommarive 9, 38123 Trento, Italy
}

Received 30 September 2014; accepted in revised form 30 November 2014

\begin{abstract}
Nanocomposite fibers of isotactic polypropylene - fumed silica AR805 were prepared by melt compounding using a two-step process: melt-spinning and hot drawing at various draw ratios up to 15. Transmission electron microscopy revealed uniform dispersion of the silica nanoparticles in polypropylene matrix, although at higher concentrations and lower draw ratios the nanoparticles showed increasing tendency to form small agglomerates. On the other hand, at low concentrations the uniform distribution of fumed silica improved mechanical properties of the composite fibers, especially at higher draw ratios. Crystallinity and melting temperature of fibers were found to significantly increase after drawing.

Elastic modulus at draw ratio $=10$ rose from 5.3 GPa for neat PP up to 6.2-8.1 GPa for compositions in the range $0.25-2 \mathrm{vol} \%$ of the filler. Moreover, higher tensile strength and creep resistance were achieved, while strain at break was rather insensitive to the filler fraction. Considering all experimental results, a failure model was proposed to explain the toughness improvement during the drawing process by the induced orientation of polymer chains and the formation of voids.
\end{abstract}

Keywords: polypropylene, fibers, nanocomposites, drawing, mechanical properties

\section{Introduction}

Significant growth of polypropylene (PP) usage can be attributed to a combination of many factors, e.g. a good balance of physical and chemical properties. Owing to plausible melt rheology and thermal properties, PP-based materials can be processed by various technologies, e.g. injection molding, calendaring, air-quenched blow films, spinning technology, spunbond process [1]. Moreover, low density, excellent thermal stability, chemical inertness along with wide design flexibility and simplicity of recycling make PP an attractive construction material. Many studies have been performed to improve mechanical properties of PP fibers and films since 1964. PP can easily be drawn and crystallized so that high degrees of orientation and crystallinity can be achieved. The maximum values of Young's modulus and tensile strength of PP fibers reported in the literature are 36-40 and $1.5 \mathrm{GPa}$, respectively [2]. Fibers of PP are employed in many end-use products thanks to their properties such as low density, resistance to moisture and chemicals, sufficient strength and easy processing [3]. PP fiber's properties can be enhanced by melt mixing with nanosized particles like carbon nanotubes [4-6] and montmorillonite [7, 8]. Nowadays, many reports have been focused on the addition of silica and/or fumed nanosilica (FS) to enhance mechanical properties of

\footnotetext{
*Corresponding author, e-mail: luca.fambri@unitn.it

(C) BME-PT
} 
polyolefins [9-13], PP fibers [12-14] and synthetic rubbers [15].

Synthetic amorphous silicon dioxide is manufactured via the hydrolysis of chlorosilanes in an oxygen-hydrogen gas flame. Resulting fumed silica (FS) is a fine, white, odorless and tasteless amorphous powder. Owing to its completely amorphous state it is considered non-toxic and non-irritating, in contrast to crystalline silica which is carcinogenic. FS surface contains $\mathrm{Si}-\mathrm{O}-\mathrm{Si}$ units and $\mathrm{Si}-\mathrm{OH}$ bonds which are highly reactive so that FS can easily be modified trough chemical functionalization. Besides, the hydrophilic surface of fumed silica is characterized by high surface energy. In general, it is important to deactivate the FS surface by using alkylchlorosilanes or alkylsilazanes before mixing with polyolefines. This treatment lowers the surface energy and changes the FS character from hydrophilic to hydrophobic [16].

It has been demonstrated that the introduction of a small amount of FS into a polyolefin matrix may lead to substantial improvements of the mechanical properties of the resulting composite [11]. Rottstegge and coworkers [12] tested PP (MFI $=15 \mathrm{~g} / 10 \mathrm{~min})$ fibers reinforced by fumed silica. The obtained materials were of good quality, however, modulus, strain and stress at break were only slightly higher than those of neat PP. Srisawat and coworkers [13, 14] studied the influence of FS addition on the properties of PP fibers using PP with high melt flow rate (MFI = $25 \mathrm{~g} / 10 \mathrm{~min}$ ). They observed not only a higher thermal stability and nucleation effect of the nanofiller, but also a remarkable increase in the tensile strength, as consequence of the incorporation of elongated and flattened silica particles during the spinning process. D'Amato et al. [9] used high density polyethylene with low melt flow index as a matrix to produce fibers by means of a two-step process: extrusion and drawing. Fiber stiffness was remarkably improved by nanofiller presence, especially at elevated draw ratios, without affecting the tensile properties at break. Also creep compliance showed a reduction in comparison with neat HDPE fibers. Enhancement of these properties was related to the alignment of silica aggregates along the strain direction, which was confirmed by TEM analysis.

To the best of our knowledge, no papers can be found in the current literature dealing with the effect of fumed silica reinforcement in nanocomposite fibers made of PP with low melt flow rate. In this contribution we have selected Aerosil ${ }^{\mathbb{R}}$ AR 805 which - due to the surface modification obtained by octylsilane - has relatively long organic chains allowing for larger strains at break of the composites, as shown elsewhere [17]. In particular, our attention was focused on the addition of low amounts of FS to PP in order to improve the mechanical properties of resulting fibers. The fibers were melt-compounded by twin-screw extruder and then drawn at $145^{\circ} \mathrm{C}$ up to elevated draw ratio (DR). Mechanical and thermal measurements of the fibers were used to evaluate the effect of FS with regard to its concentration and to the selected processing procedure. Simultaneously, the effects of the fiber composition and of DR on resulting morphology were studied.

\section{Experimental section}

\subsection{Materials and sample preparation}

\subsubsection{Materials}

Isotactic polypropylene (Moplen HP500, melt flow rate $1.8 \mathrm{~g} / 10 \mathrm{~min}$ at $230^{\circ} \mathrm{C}$ and $2.16 \mathrm{~kg}$, density at $23^{\circ} \mathrm{C}=0.9 \mathrm{~g} / \mathrm{cm}^{3}$ ) in the form of pellets was supplied by Basell Polyolefins (Ferrara, Italy). Fumed silica Aerosil ${ }^{\circledR}$ R805 was kindly supplied by Evonik (Essen, Germany). Aerosil ${ }^{\mathbb{}} \mathrm{R} 805$ is a hydrophobic silica (surface treated with octylsilane) with a specific surface area $150 \mathrm{~m}^{2} \cdot \mathrm{g}^{-1}$, mean particle size of about $12 \mathrm{~nm}$ and a bulk density of $1.84 \mathrm{~g} \cdot \mathrm{cm}^{-3}$ at $23^{\circ} \mathrm{C}$. Before the processing, FS powders were dried for $24 \mathrm{~h}$ at $80^{\circ} \mathrm{C}$ in a vacuum oven. Nanocomposites were marked with the silica abbreviation (AR805) and the filler content. As an example, AR805-2 indicates a nanocomposite sample filled with $2 \mathrm{vol} \%$ of fumed silica Aerosil ${ }^{\circledR} \mathrm{R} 805$.

\subsubsection{Fiber spinning}

Monofilament fibers with the FS fraction between 0.25 and $2 \mathrm{vol} \%$ (Table 1 ) were produced by Thermo Haake (Karlsruhe, Germany) PTW16 intermeshing co-rotating twin screw extruder (screw diameter $16 \mathrm{~mm}, L / D$ ratio 25 , rod die diameter $1.65 \mathrm{~mm}$ ). The temperature profile from the hopper to rod die was gradually increased $\left(T_{1}=130^{\circ} \mathrm{C}, T_{2}=200^{\circ} \mathrm{C}\right.$, $\left.T_{3}=210^{\circ} \mathrm{C}, T_{4}=220^{\circ} \mathrm{C}, T_{5}=230^{\circ} \mathrm{C}\right)$. The extruder screws rotation was optimized in the range of 8 $10 \mathrm{rpm}$ depending on the material composition in order to produce fibers having a diameter of about $500 \mu \mathrm{m}$, as reported in Table 1, with an almost constant diameter ratio between die diameter and fiber diameter of $3.29 \pm 0.03$. The spun fibers were fast 
Table 1. Designation and composition of the PP nanocomposite fibers. Average diameter of as-spun fibers $(D R=1)$ and selected drawn fibers at nominal draw ratio $D R 5,10$ and 15 .

\begin{tabular}{|c|c|c|c|c|c|c|}
\hline \multirow[b]{2}{*}{ Material } & \multirow{2}{*}{$\begin{array}{c}\text { PP } \\
{[\text { vol\%] }}\end{array}$} & \multirow{2}{*}{$\begin{array}{c}\text { Fumed silica } \\
\text { [vol\%] }\end{array}$} & \multicolumn{4}{|c|}{ Fiber diameter } \\
\hline & & & $\begin{array}{c}\text { DR }=1 \\
{[\mu \mathrm{m}]}\end{array}$ & $\begin{array}{c}\mathrm{DR}=5 \\
{[\mu \mathrm{m}]}\end{array}$ & $\begin{array}{c}\mathrm{DR}=10 \\
{[\mu \mathrm{m}]}\end{array}$ & $\begin{array}{c}\mathrm{DR}=15 \\
{[\mu \mathrm{m}]}\end{array}$ \\
\hline PP & 100 & 0 & $495 \pm 6$ & $230 \pm 3$ & $158 \pm 3$ & $128 \pm 2$ \\
\hline AR805-0.25 & 99.75 & 0.25 & $504 \pm 9$ & $229 \pm 2$ & $157 \pm 3$ & $130 \pm 2$ \\
\hline AR805-0.5 & 99.50 & 0.5 & $506 \pm 19$ & $233 \pm 14$ & $157 \pm 2$ & $130 \pm 2$ \\
\hline AR805-1 & 99.0 & 1 & $500 \pm 7$ & $220 \pm 2$ & $154 \pm 1$ & $129 \pm 2$ \\
\hline AR805-2 & 98.0 & 2 & $502 \pm 15$ & $227 \pm 3$ & $157 \pm 2$ & $130 \pm 3$ \\
\hline
\end{tabular}

cooled in water at room temperature in order to eliminate orientation and drawing of the fibers immediately after the extrusion, and wrapped around a bobbin of diameter $40 \mathrm{~mm}$ rotating at $8 \mathrm{~m} / \mathrm{min}$.

\subsubsection{Fiber drawing}

The spun fibers were drawn in a hot-plate drawing apparatus $1.4 \mathrm{~m}$ length (SSM-Giudici srl, Galbiate, LC, Italy - www.ssm-giudici.it) at $145^{\circ} \mathrm{C}$, similarly to the maximum drawing temperature $\left(150^{\circ} \mathrm{C}\right)$ selected by Joshi and Viswanathan [18] in order to obtain highly extended fibers. As-spun fibers were unreeled and wound by using acrylic bobbins of $40 \mathrm{~mm}$ diameter rotating from 10 up to $150 \mathrm{rpm}$, corresponding to a constant feeding rate of $1.26 \mathrm{~m} / \mathrm{min}$ and maximum collecting rate of about $190 \mathrm{~m} / \mathrm{min}$ (nominal draw ratio of 15).

The fiber draw ratio $(D R)$ is commonly defined as the ratio between the collection $\left(R_{\mathrm{c}}\right)$ and the feeding $\left(R_{\mathrm{f}}\right)$ rate, and assuming a constant volume, it can be calculated according to Equation (1):

$D R=\left(\frac{D_{\mathrm{i}}}{D_{\mathrm{f}}}\right)^{2}$

where $D_{\mathrm{i}} / D_{\mathrm{f}}$ are the initial and final diameter of the fiber. The diameter was measured by using an optical microscope connected to image processing software $\left(\right.$ Image $\left.{ }^{\circledR}\right)$. Fibers with various draw ratios from $D R=3$ up to $D R=15$ were produced. Nominal draw ratio of 1 is referred to as-spun fibers, whereas $D R=5,10$ and 15 corresponds to the nominal draw ratio of drawn fiber with the diameter reported in Table 1.

\subsection{Experimental techniques}

Dispersion of FS in the PP matrix was visualized by transmission electron microscopy (TEM). Specimens for TEM analysis were prepared by means of an ultramicrotome by cutting the fibers perpendicularly to their axis. TEM micrographs were taken with a microscope FEI Tecnai G2 Spirit (Brno, Czech Republic) using the bright field imaging at $120 \mathrm{kV}$. Differential scanning calorimetry (DSC) analysis was performed by using a Mettler DSC30 calorimeter (Schwarzenbach, Switzerland). Fiber samples of about $15 \mathrm{mg}$ were placed in aluminum crucibles of $160 \mu \mathrm{L}$ and were heated from 0 up to $250^{\circ} \mathrm{C}$ with a heating-cooling-heating cycle at $\pm 10^{\circ} \mathrm{C} / \mathrm{min}$ under flushing nitrogen at $100 \mathrm{~mL} / \mathrm{min}$. Melting temperature and crystallization temperature were registered during the scans. The crystallinity percentage $X$ was calculated according to Equation (2) relating the measured melting enthalpy $\Delta H_{\mathrm{i}}$, the standard enthalpy of the fully crystalline PP (207 J.g $\left.{ }^{-1}[19]\right)$ and the weight fraction of nanofiller $f$ :

$X_{\mathrm{PP}}=100 \frac{\Delta H_{\mathrm{i}}}{207 \cdot(1-f)}$

Quasi-static tensile mechanical properties of asspun and all drawn fibers were measured at room temperature by using an Instron ${ }^{\circledR} 4502$ (Norwood, MA, USA) tensile dynamometer equipped with a load cell of $100 \mathrm{~N}$. Single filaments of various diameters $(0.5 \mathrm{~mm}-0.1 \mathrm{~mm})$ and of the gauge length $30 \mathrm{~mm}$ were uniaxially tested at a cross-head speed $50 \mathrm{~mm} / \mathrm{min}$. Elastic modulus was determined according to ISO 527 standard as a secant value between the strain levels of 0.05 and $0.25 \%$. For each sample 5 specimens were tested and the average values were calculated.

Dynamic mechanical thermal analysis (DMTA) was conducted by a dynamic mechanical analyzer DMA Q800 from TA Instruments (New Castle, DE, USA). Experiments were carried out in the tensile mode by using a fiber clamp (gauge length of $10 \mathrm{~mm}$; prestress of $0.01 \mathrm{~N}$; sinusoidal strain with a frequency of $1 \mathrm{~Hz}$ and amplitude of 64 micron) from -125 to $100^{\circ} \mathrm{C}$ at a heating rate of $3^{\circ} \mathrm{C} / \mathrm{min}$.

Creep response of drawn (DR 10 and 15) and undrawn fibers at $30^{\circ} \mathrm{C}$ was studied by using a 
dynamic mechanical analyzer DMA Q800 from TA Instruments (New Castle, DE, USA): gauge length of $10 \mathrm{~mm}$; creeping time of $3600 \mathrm{~s}$. A constant stress of $3 \mathrm{MPa}$ corresponding to about $10 \%$ of the yield stress of undrawn fibers was chosen as the creep stress.

\section{Results and discussion}

It is well known that uniform filler dispersion and its good adhesion to polymer matrix are fundamental for improving mechanical properties of the composites. Complete and uniform dispersion is important for achieving a large interface and, consequently, extensive interfacial bonding that ensures a good interfacial stress transfer [20]. Thus, microstructure analysis by TEM was focused on the fumed silica distribution in PP matrix.

\subsection{Microstructure characterization}

TEM images of ultramicrotomed cross sections of the nanofilled PP-AR805 fibers with selected nanofiller fractions and/or draw ratios are presented in Figures 1,2. A set of low-magnification micrographs
(Figure 1) of all studied composites shows that the silica particles are dispersed quite uniformly in the polymer matrix, but frequently they tend to form small agglomerates. In general, the amount and size of the agglomerates increases with the increasing filler percentage: at the lowest concentration (AR8050.25 ; Figures $1 \mathrm{a}-1 \mathrm{c})$ the agglomerates are rare, whereas at the highest concentration (AR805-2; Figures 1d-1f) the average number and size of the agglomerates grows; morphology of samples with medium concentrations (AR805-0.5 and AR805-1; not shown for the sake of brevity) is in between the two extremes. Further inspection of the TEM micrographs reveals that the silica nanoparticle agglomerates are partially destroyed at higher draw ratios. The effect is stronger for composites with higher nanoparticle concentrations (Figures 1d-1f). TEM micrographs with higher magnifications (Figure 2) evidence that silica nanoparticles are quite well fixed in the PP matrix even if they are agglomerated, because the matrix penetrates inside the agglomerates and the interface is not sharp but diffuse, which indicates good interfacial adhesion.

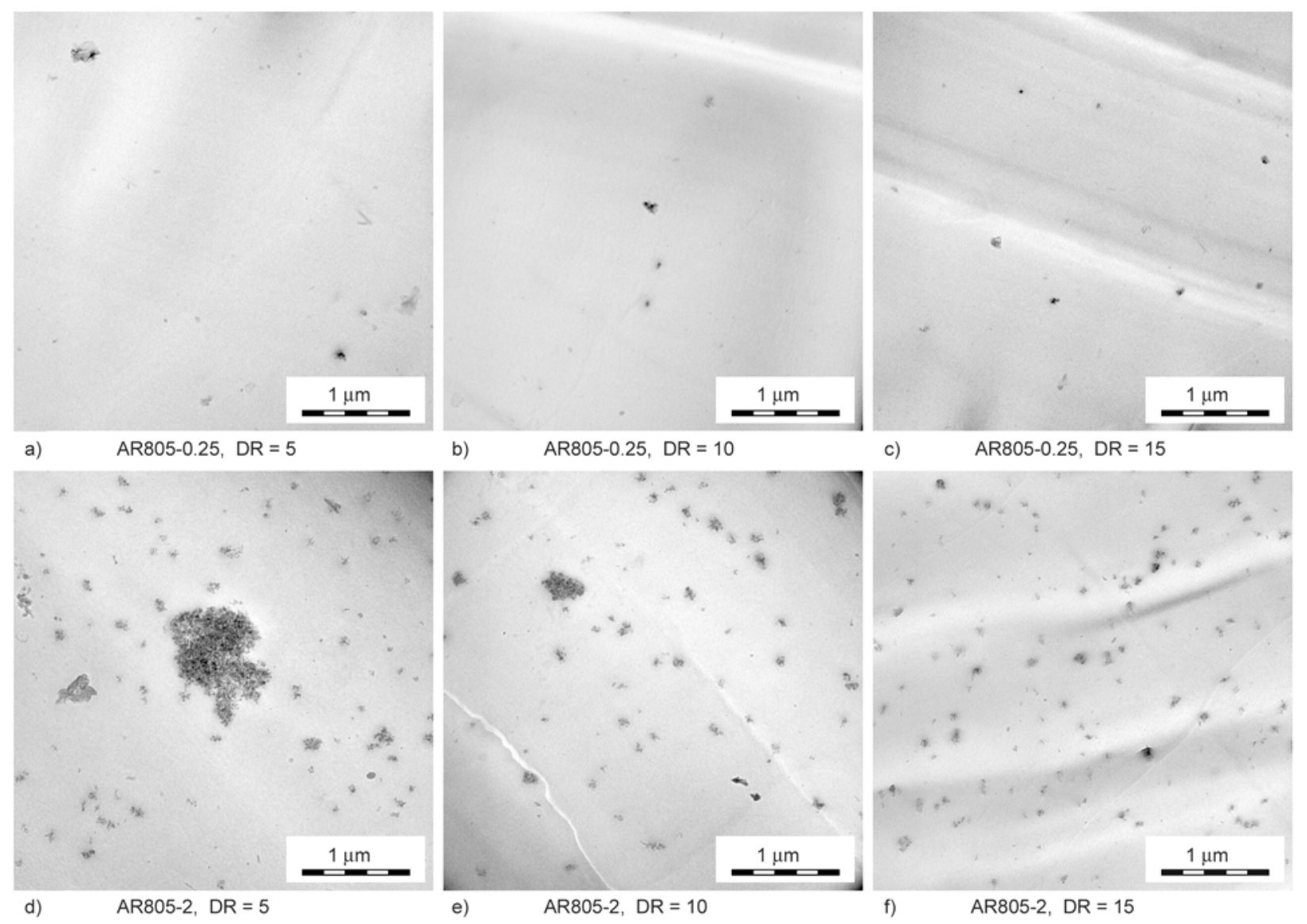

Figure 1. TEM micrographs of AR805 at various silica nanoparticle concentrations and draw ratios 

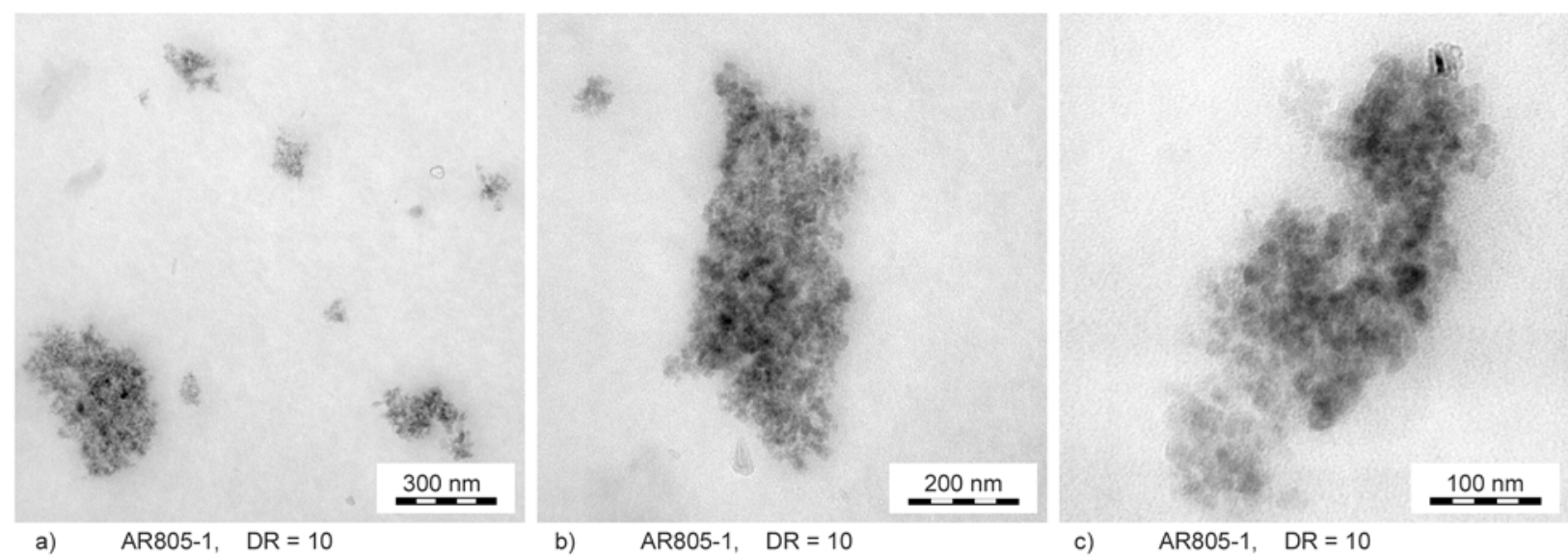

Figure 2. Higher magnification TEM micrographs of nanocomposite fibers AR805-1, illustrating good adhesion between nanosilica particles and iPP matrix

\subsection{Differential scanning calorimetry}

DSC results of the heating-cooling-heating cycle of the neat and nanocomposite PP fibers with different draw ratios are summarized in Table 2. Selected thermograms are depicted in Figure $3 a-3 c$, where a single sharp melting peak is observed for the fibers with $D R=1$ and 5, while for $D R=10$ and 15 distinct multiple melting peaks appear. This behav-

Table 2. Results of the DSC analysis $\left(1^{\text {st }}\right.$ heating - cooling $-2^{\text {nd }}$ heating); onset of melting temperature $\left(T_{\mathrm{m}}\right.$ onset), melting temperature $\left(T_{\mathrm{m}}\right)$, crystallinity $(\chi)$ and crystallization temperature $\left(T_{\mathrm{c}}\right)$ for neat and nanocomposite PP fibers at selected nominal draw ratio $(D R=1,5,10$ and 15$)$

\begin{tabular}{|c|c|c|c|c|c|c|}
\hline \multirow{2}{*}{\multicolumn{2}{|c|}{ Material }} & \multicolumn{2}{|c|}{$1^{\text {st }}$ heating } & \multicolumn{2}{|c|}{ Cooling } & \multirow{2}{*}{$\begin{array}{c}\mathbf{2}^{\text {nd }} \text { heating } \\
\mathbf{T}_{\mathbf{m} 2} \\
{\left[{ }^{\circ} \mathrm{C}\right]}\end{array}$} \\
\hline & & $\begin{array}{c}\mathbf{T}_{\mathbf{m} 1} \\
{\left[{ }^{\circ} \mathbf{C}\right]}\end{array}$ & $\begin{array}{c}\mathbf{X}_{\mathbf{c}} \\
{[\%]}\end{array}$ & $\begin{array}{c}\mathbf{T}_{\mathbf{c}} \\
{\left[{ }^{\circ} \mathbf{C}\right]}\end{array}$ & $\begin{array}{c}\mathbf{X}_{\mathbf{c}} \\
{[\%]}\end{array}$ & \\
\hline \multirow{4}{*}{ ิિ } & $D R=1$ & 165.1 & 36.4 & 111.5 & 44.7 & 167.1 \\
\hline & $D R=5$ & 172.5 & 45.0 & 112.8 & 49.0 & 164.6 \\
\hline & $D R=10$ & 179.7 & 50.4 & 114.1 & 47.2 & 164.7 \\
\hline & $D R=15$ & 178.0 & 53.0 & 114.6 & 48.8 & 164.2 \\
\hline \multirow{4}{*}{ 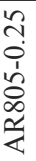 } & $D R=1$ & 161.7 & 41.5 & 114.0 & 47.6 & 164.8 \\
\hline & $\mathrm{DR}=5$ & 170.0 & 49.6 & 115.8 & 47.8 & 164.5 \\
\hline & $D R=10$ & 174.0 & 56.2 & 115.0 & 47.5 & 165.1 \\
\hline & $D R=15$ & 180.7 & 53.0 & 112.0 & 46.4 & 164.9 \\
\hline \multirow{4}{*}{$\begin{array}{l}n \\
0 \\
1 \\
2 \\
\infty \\
\infty \\
1 \\
4\end{array}$} & $D R=1$ & 160.7 & 43.0 & 114.3 & 48.6 & 164.6 \\
\hline & $D R=5$ & 172.0 & 45.0 & 111.5 & 45.6 & 164.2 \\
\hline & $D R=10$ & 174.1 & 49.2 & 111.1 & 45.6 & 165.8 \\
\hline & $D R=15$ & 180.0 & 52.7 & 113.0 & 46.7 & 165.5 \\
\hline \multirow{4}{*}{ 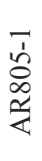 } & $D R=1$ & 162.3 & 38.4 & 114.4 & 47.0 & 164.6 \\
\hline & $D R=5$ & 165.2 & 45.7 & 112.1 & 46.2 & 165.4 \\
\hline & $D R=10$ & 175.8 & 50.5 & 109.7 & 48.0 & 167.1 \\
\hline & $D R=15$ & 182.4 & 52.0 & 112.7 & 42.0 & 165.4 \\
\hline \multirow{4}{*}{ 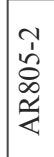 } & $D R=1$ & 162.5 & 41.1 & 114.4 & 49.2 & 165.4 \\
\hline & $D R=5$ & 167.9 & 43.4 & 110.2 & 46.5 & 165.2 \\
\hline & $D R=10$ & 179.0 & 51.2 & 114.0 & 47.3 & 165.5 \\
\hline & $D R=15$ & 177.4 & 53.5 & 113.8 & 46.5 & 163.9 \\
\hline
\end{tabular}

ior is related to the difference in the crystal forms and the degree of perfection and/orientation achieved during drawing.

Comparison of the values of crystallinity, melting $\left(T_{\mathrm{m}}\right)$ and crystallization $\left(T_{\mathrm{c}}\right)$ temperatures indicates interesting differences between as-spun fibers for neat as well as nanofilled PP. Higher $T_{\mathrm{c}}$ (about $114^{\circ} \mathrm{C}$ vs. $111^{\circ} \mathrm{C}$ for neat PP) and crystallinity content (38-43\% vs. $36 \%$ for neat PP), along with lower $T_{\mathrm{m}}$ values $\left(160-162^{\circ} \mathrm{C}\right.$ vs. $165^{\circ} \mathrm{C}$ for neat PP) were observed for as-spun nanocomposite fibers. In the literature, starting from PP at relatively high melt flow $(M F=12$ and $25 \mathrm{~g} / 10 \mathrm{~min})$ slightly lower $T_{\mathrm{m}}$ values were already reported for both as-spun and drawn nanocomposite polyolefine fibers [18, 21], and correspondently lower crystallinity content and $T_{\mathrm{c}}$ values were observed. On the other hand, there are reports where growth of $T_{\mathrm{m}}$ was indicated along with lower crystallinity $[7,22]$. Thus it can be concluded that higher crystallinity content and higher crystallization temperature in cooling reveal a possible nucleating role of FS.

The increase in the orientation of fiber structure upon the solid state drawing (Table 2) accounts not only for a higher degree of crystallinity (from about $36 \%$ up to $53 \%$ ), but also for a significant increase in the melting temperature (from $161-165^{\circ} \mathrm{C}$ up to $174-182^{\circ} \mathrm{C}$ ). Obviously, the higher the draw ratio, the higher the orientation of the polymer chains and, consequently, the faster the crystallization in the draw direction [23]. Higher crystallinity observed after the drawing is a typical effect, which is related to the high degree of the order and continuity of the crystalline phase, as presented by Srisawat et al. [13] for fibers drawn at $110^{\circ} \mathrm{C}$ with 

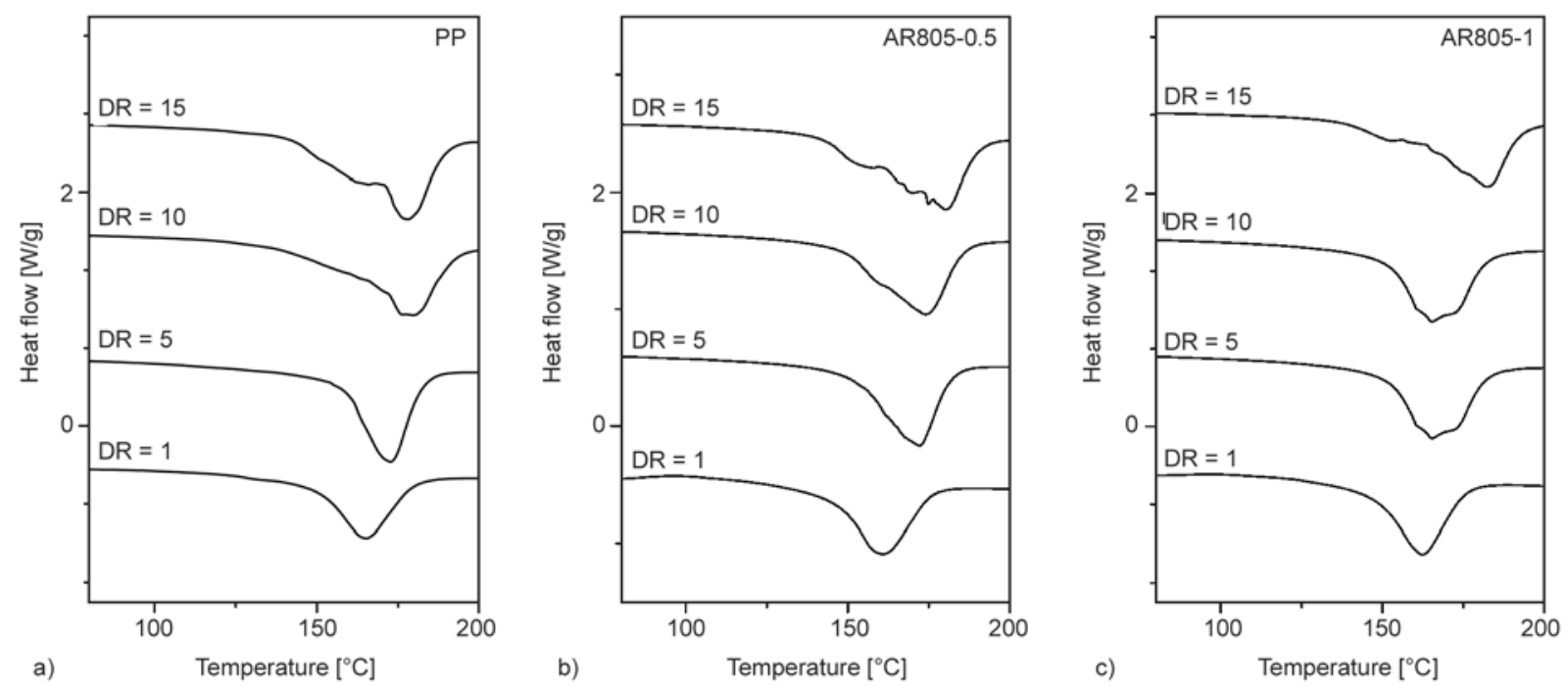

Figure 3. The first heating DSC thermograms of a) neat PP, b) AR805-0.5, and c) AR805-1 nanocomposite fibers at different draw ratios

fumed silica and high melt flow polypropylene (25 g/10 min), but showing also slight decrease of melting temperature. On the other hand, the parallel increase of crystallinity and melting temperature shown in Table 2, could directly be related to the low melt flow PP, as consequence of a combined effect of both the high drawing orientation and the high drawing temperature. Analogous results were obtained for nanocomposite fibers with low melt flow HDPE $\left(0.9 \mathrm{~g} / 10 \mathrm{~min}\right.$ at $\left.190^{\circ} \mathrm{C} / 2.16 \mathrm{~kg}\right)$ containing organically modified hydrotalcite [24], that showed after drawing at $125^{\circ} \mathrm{C}$ a relevant increase of both melting temperature (from $132-133^{\circ} \mathrm{C}$ up to $140-146^{\circ} \mathrm{C}$ ) and crystallinity content (from about $50 \%$ up to $74-78 \%$ ). In both cases, the effect of drawing could be interpreted as the transformation of lower perfection crystals in highly ordered structure at higher melting temperature, and it is also proportional to the orientation of non-crystalline regions.

As already mentioned, polyolefin fibers show various kinds of improvements, so that it is difficult to obtain clear information on the effect of FS on the crystallization behavior of polypropylene fibers. If the fiber properties at the highest $D R=15$ are compared, some slightly higher values of crystallinity and $\mathrm{Tm}$ can be seen for composites with FS.

It can be concluded from the data obtained for the as-spun fibers that the effect of FS on the nucleation process is quite evident, while in the case of the drawn fibers is rather blurred. The most significant result is the increase of the melting temperature of both PP and nanofilled PP fibers after drawing, probably related to the high drawing temperature of high molecular weight polymer.

\subsection{Mechanical properties}

Representative stress - strain curves of the quasistatic tensile tests for as-spun $(D R=1)$ and drawn fibers with $D R=15$ at various nanofiller content are reported in Figure 4a and 4b, respectively. The most relevant mechanical properties are summarized in Table 3. It is important to note that undrawn fibers manifest a clear yield point at a low strain followed by a wide plateau (of cold drawing at a constant stress) and a strain hardening region until the break point. Drawing process produces a strong orientation of the macromolecules along the draw direction and the strain-induced crystallization in the amorphous regions, which accounts for the increase in the fiber stiffness and the disappearance of yielding phenomena.

Tensile modulus $(E)$ of the PP-FS fibers as a function of the draw ratio is shown in Figure 5. It is evident that FS particles raise the fiber stiffness, especially at higher draw ratios. The highest improvements were obtained for the compositions with 0.25 and $0.5 \mathrm{vol} \% \mathrm{FS}$, whose elastic modulus reached 8.1 and $7.3 \mathrm{GPa}$, respectively (in comparison to $5.3 \mathrm{GPa}$ of the neat PP). A negative effect of high concentrations of nanosilica on modulus observed for composition with 2 vol\% of filler is even more visible not only for $D R=5$ (see Figure 1d), but also for higher draw ratio $(D R>10)$, which can be explained in 

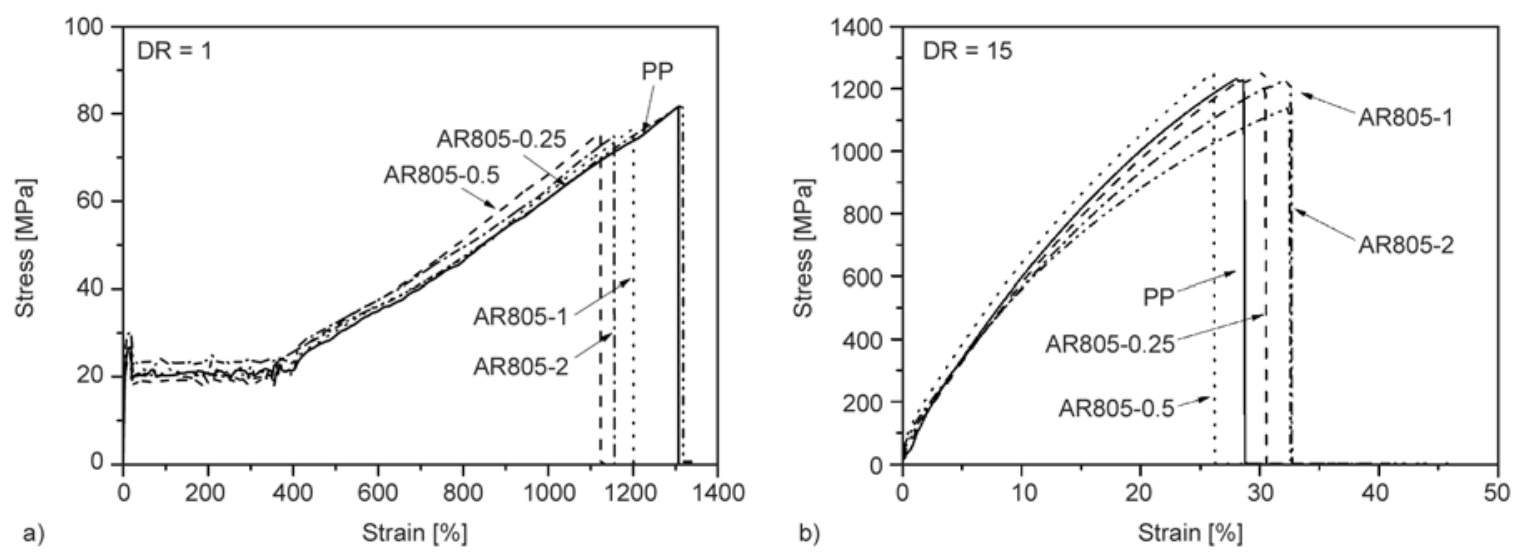

Figure 4. a) Representative stress-strain curves of neat and nanocomposite PP fibers a) as-spun fibers $(D R=1)$ and b) drawn fibers with draw ratio $D R=15$

Table 3. Mechanical properties of neat and nanofilled PP fibers at selected nominal draw ratios $(D R=1,5,10$ and 15$)$

\begin{tabular}{|c|c|c|c|c|c|c|c|c|}
\hline Material & DR & $\begin{array}{c}\text { Elastic } \\
\text { modulus } \\
\text { [GPa] }\end{array}$ & $\begin{array}{c}\text { Stress at } \\
\text { break } \\
\text { [MPa] }\end{array}$ & $\begin{array}{c}\text { Strain at } \\
\text { break } \\
{[\%]} \\
\end{array}$ & $\begin{array}{c}\text { True } \\
\text { strength }^{\mathrm{a}} \\
{[\mathrm{MPa}]}\end{array}$ & $\begin{array}{c}\text { Mechanical } \\
\text { draw ratio } \\
\lambda_{\text {MEC }} \\
\end{array}$ & $\begin{array}{c}\text { Total draw } \\
\quad \text { ratio } \\
\lambda_{\text {TOT }} \\
\end{array}$ & $\begin{array}{c}\text { Draw } \\
\text { stiffening } \\
\text { factor }^{b}\end{array}$ \\
\hline \multirow{4}{*}{ PP } & 1 & $0.48 \pm 0.01$ & $83 \pm 4$ & $1260 \pm 15$ & 1123 & 13.6 & 148.1 & 1.0 \\
\hline & 5 & $1.71 \pm 0.15$ & $374 \pm 13$ & $185 \pm 11$ & 1066 & 2.85 & 153.3 & 3.6 \\
\hline & 10 & $5.30 \pm 0.15$ & $944 \pm 25$ & $53 \pm 5$ & 1444 & 1.53 & 173.4 & 11.0 \\
\hline & 15 & $7.88 \pm 0.35$ & $1240 \pm 50$ & $34 \pm 3$ & 1661 & 1.34 & 215.8 & 16.4 \\
\hline \multirow{4}{*}{ AR805-0.25 } & 1 & $0.54 \pm 0.01$ & $82 \pm 2$ & $1275 \pm 55$ & 1127 & 13.7 & 149.7 & 1.0 \\
\hline & 5 & $2.27 \pm 0.15$ & $538 \pm 14$ & $70 \pm 10$ & 914 & 1.7 & 91.4 & 4.2 \\
\hline & 10 & $8.10 \pm 0.17$ & $1117 \pm 25$ & $41 \pm 3$ & 1575 & 1.41 & 159.7 & 15.0 \\
\hline & 15 & $9.10 \pm 0.52$ & $1277 \pm 11$ & $36 \pm 4$ & 1737 & 1.36 & 219.1 & 17.0 \\
\hline \multirow{4}{*}{ AR805-0.5 } & 1 & $0.60 \pm 0.01$ & $78 \pm 3$ & $1125 \pm 45$ & 955 & 12.2 & 133.4 & 1.0 \\
\hline & 5 & $2.16 \pm 0.01$ & $404 \pm 11$ & $126 \pm 13$ & 913 & 2.26 & 121.5 & 3.6 \\
\hline & 10 & $7.30 \pm 0.5$ & $1260 \pm 25$ & $39 \pm 5$ & 1751 & 1.39 & 157.5 & 12.2 \\
\hline & 15 & $9.00 \pm 0.35$ & $1273 \pm 20$ & $33 \pm 4$ & 1693 & 1.33 & 214.2 & 15.0 \\
\hline \multirow{4}{*}{ AR805-1 } & 1 & $0.61 \pm 0.01$ & $76 \pm 2$ & $1282 \pm 25$ & 990 & 13.0 & 150.0 & 1.0 \\
\hline & 5 & $2.36 \pm 0.15$ & $414 \pm 20$ & $71 \pm 3$ & 824 & 2.0 & 92.0 & 3.9 \\
\hline & 10 & $7.10 \pm 0.35$ & $1172 \pm 35$ & $36 \pm 10$ & 1418 & 1.21 & 154.1 & 11.6 \\
\hline & 15 & $8.40 \pm 0.24$ & $1175 \pm 45$ & $32 \pm 7$ & 1492 & 1.27 & 212.6 & 13.8 \\
\hline \multirow{4}{*}{ AR805-2 } & 1 & $0.65 \pm 0.02$ & $72 \pm 2$ & $1108 \pm 40$ & 870 & 12.1 & 131.5 & 1.0 \\
\hline & 5 & $1.93 \pm 0.12$ & $376 \pm 15$ & $100 \pm 12$ & 752 & 2.0 & 107.6 & 3.0 \\
\hline & 10 & $6.16 \pm 0.65$ & $936 \pm 10$ & $33 \pm 11$ & 1245 & 1.33 & 150.7 & 9.5 \\
\hline & 15 & $7.51 \pm 0.30$ & $1175 \pm 40$ & $31 \pm 3$ & 1539 & 1.31 & 211.0 & 11.6 \\
\hline
\end{tabular}

acalculated according to Equation (4)

${ }^{b}$ calculated as the ratio of the modulus of drawn fiber and the modulus of as-spun fiber.

terms of the aggregate formation and incomplete filler dispersion as confirmed by TEM analysis (Figure 1).

Stress at break is plotted against $D R$ in Figure 6 showing that drawn PP-FS fibers with low filler contents have higher strength than neat PP. If $D R=$ 10 is taken for comparison, stress at break reached $1117 \mathrm{MPa}$ for AR805-0.25 and $1260 \mathrm{MPa}$ for AR805-0.5, with respect to $944 \mathrm{MPa}$ for neat PP. It can be noticed that for the compositions up to 0.5 vol $\%$ of FS, stress at break was higher over the entire interval of $D R$ in comparison to neat $\mathrm{PP}$, while for the compositions with nanofiller fraction higher than $1 \mathrm{vol} \%$ the obtained values were slightly lower. These findings are in conformity with available literature data. In the case of low nanofiller content, some authors attributed the enhancement of tensile properties to a better orientation of both silicate layers and polymer chains during the fiber spinning $[20,25]$. Some other researchers $[8,13,18]$ confirmed that better mechanical properties of PP fibers fibers could be obtained with low nanofiller contents such as $0.25-0.5 \mathrm{vol} \%$, whereas at higher filler concentrations ( $>1 \mathrm{vol} \%$ ), the aggregation of the silica particles may deteriorate the fiber mechanical properties. 


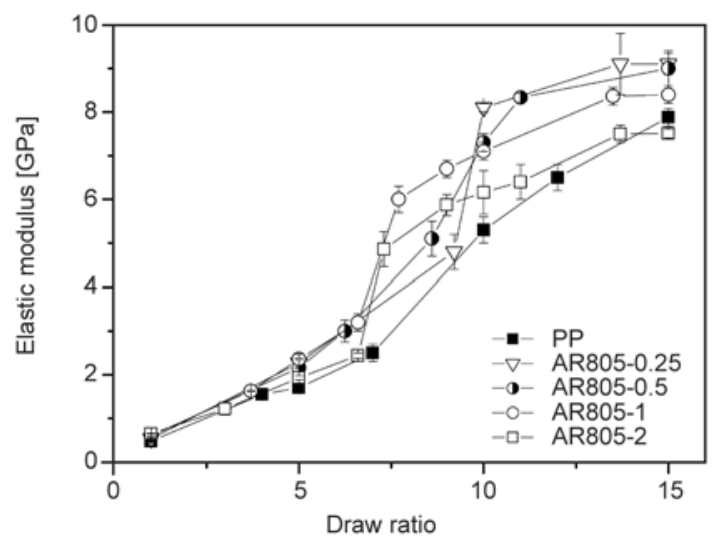

Figure 5. Elastic modulus of neat and nanocomposite PP fibers with different fractions of fumed silica as a function of draw ratio $(D R)$

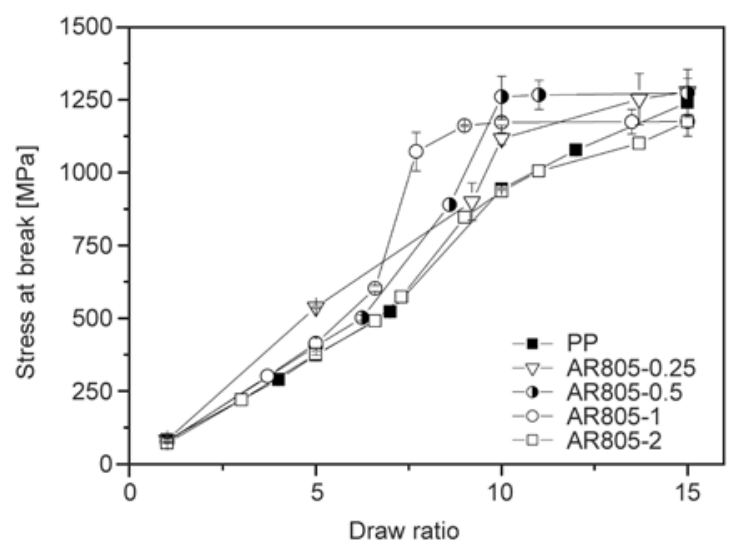

Figure 6. Stress at break of neat and nanocomposite PP fibers with different fractions of fumed silica as a function of draw ratio $(D R)$

Figure 7 confirms previous observations that the higher the draw ratio the lower the strain at break. In the case of the as-spun nanocomposite fibers, strain at break was slightly higher for the compositions with 0.25 and 1 vol\% of the filler, when compared with that of neat PP (Table 3 and Figure 7). In general, the presence of the nanofiller does not markedly affect the strain at break of the prepared fibers. For example, both PP and AR805-1 fibers show similar strains at break of about $1270 \%$ and $33 \%$ for $D R=1$ and $D R=15$, respectively.

We can conclude that the simultaneous increases in modulus and stress at break are not accompanied by significant changes of the strain at break. This kind of mechanical behavior is in agreement with previous reports on nanosilica composites where better mechanical properties were achieved through good dispersion of silica nanoparticles [9, 26, 27]. The observed toughening effect in the PP-FS fibers is

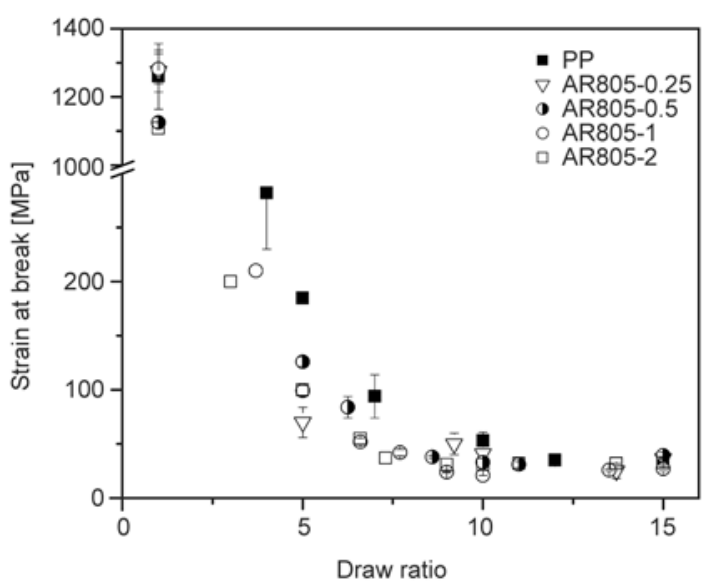

Figure 7. Strain at break of neat and nanocomposite PP fibers with different fractions of fumed silica as a function of draw ratio $(D R)$

very particular and promising, because the stiffening effect in nanocomposites is commonly accompanied by the reduction of the tensile strain at break. In order to obtain more information on spinnability and drawability, the mechanical draw ratio $\left(\lambda_{\mathrm{MEC}}\right)$, the true strength $\left(\sigma_{\mathrm{MAX}}\right)$, the processing draw ratio $\left(\lambda_{\mathrm{PRO}}\right)$ and the total draw ratio $\left(\lambda_{\text {TOT }}\right)$ of selected fibers were reported in Table 3 . As previously defined by Dabrowska et al. [28], the mechanical draw ratio $\left(\lambda_{\mathrm{MEC}}\right)$, is calculated by Equation (3):

$\lambda_{\mathrm{MEC}}=1-\frac{\varepsilon_{\mathrm{b}}}{100}$

where $\varepsilon_{\mathrm{b}}$ is the strain at break expressed in percentage. The true strength $\left(\sigma_{\mathrm{MAX}}\right)$ is defined as the stress at break $\left(\sigma_{\mathrm{b}}\right)$ multiplied by the mechanical draw ratio Equation (4):

$\sigma_{\mathrm{MAX}}=\sigma_{\mathrm{b}} \cdot \lambda_{\mathrm{MEC}}$

The processing draw ratio $\left(\lambda_{\text {PRO }}\right)$ is calculated as the ratio between the sections of the die $S_{\mathrm{d}}$ and the section of the fibers $S_{\mathrm{f}}$ according to Equation (5):

$\lambda_{\mathrm{PRO}}=\frac{S_{\mathrm{d}}}{S_{\mathrm{f}}}$

Total draw ratio $\left(\lambda_{\text {Tот }}\right)$ can be calculated from Equation (6) [29]:

$\lambda_{\mathrm{TOT}}=\lambda_{\mathrm{PRO}} \cdot \lambda_{\mathrm{MEC}}$

For the as-spun fibers, only the composite with $0.25 \mathrm{vol} \%$ of fumed silica exhibits values of true strength and total draw ratio almost equivalent to those of neat PP (see Table 3). For example, the true strength of the PP-fumed silica as-spun fibers is 
located between $\sigma_{\mathrm{MAX}}=870-1127 \mathrm{MPa}$ and their total draw ratio between $\lambda_{\mathrm{TOT}}=131-150$, whereas the corresponding values for the neat as-spun PP fibers are $1123 \mathrm{MPa}$ and 148, respectively. In the case of drawn fibers, for the compositions with 0.25 $0.5 \mathrm{vol} \%$. true strength and mechanical draw ratio are higher in comparison to those of neat PP fibers. Also, the total draw ratio indicates that fiber reinforced by a low amount of fumed nanosilica could be spun and drawn to the same levels as PP fiber, thus confirming the good processability of fumed silica nanocomposites.

In Table 3 the draw-stiffening factor, calculated as the ratio of the modulus of drawn fiber and the modulus of as spun fiber, is reported. This parameter can be useful for quantitative evaluation of the properties and drawability of composite fibers. Higher draw-stiffening factor of the nanocomposite PP fiber containing $0.25-0.5 \mathrm{vol} \%$ of fumed silica with respect to the neat PP fiber for $D R$ up to 10 is quite evident, while slightly lower values for the composites with 2 vol\% of silica are obtained.

The maximum attainable mechanical properties $\mathrm{P}_{\infty}$ (either modulus or stress at break) can be predicted by using the following equation for fitting all experimental data plotted against $1 / D R$ according to Equation (7):

$P=P_{\infty}-k_{\mathrm{p}}\left(\frac{1}{D R}\right)$

where $k_{\mathrm{p}}$ is a constant taking into account the sensitivity of the property to the drawing [30]. Following this equation, the maximum attainable elastic moduli for all our nanocomposite fibers (from 10.5 GPa for AR805-1 up to 12.7 GPa for AR805-0.5) would be higher than that of neat PP, $9.6 \mathrm{GPa}$, as reported in Table 4. Similar tendency can also be observed for the maximum attainable stress at break, that is 1.59 GPa for AR805-1 and 1.63 GPa for AR805-

Table 4. Maximum attainable values of elastic modulus $\left(E_{\infty}\right)$ and stress at break $\left(\sigma_{\infty}\right)$ of neat and nanofilled PP nanocomposite fibers, as predicted by Equation (7)

\begin{tabular}{|l|c|c|}
\hline \multicolumn{1}{|c|}{ Drawn fiber } & $\begin{array}{c}\mathbf{E}_{\infty} \\
{[\mathbf{G P a}]}\end{array}$ & $\begin{array}{c}\boldsymbol{\sigma}_{\infty} \\
{[\mathbf{G P a}]}\end{array}$ \\
\hline PP & $9.6 \pm 0.7$ & $1.49 \pm 0.10$ \\
\hline AR805-0.25 & $12.5 \pm 1.4$ & $1.63 \pm 0.08$ \\
\hline AR805-0.5 & $12.7 \pm 1.0$ & $1.88 \pm 0.16$ \\
\hline AR805-1 & $10.5 \pm 0.2$ & $1.59 \pm 0.12$ \\
\hline AR805-2 & $8.6 \pm 0.3$ & $1.27 \pm 0.11$ \\
\hline
\end{tabular}

0.25 , with respect to $1.49 \mathrm{GPa}$ of neat PP. On the other hand, the composition with 2 vol\% of FS shows the lowest extrapolated values.

\subsection{Dynamical mechanical analysis}

DMTA analysis was performed on the fibers with selected draw ratios to obtain deeper information on mechanical properties and molecular mobility. Due to a very high surface area of the nanoparticles in the PP-AR805 nanocomposites, the applied sinusoidal stress is expected to be easily transferred from the matrix onto the silica particles. Storage modulus $\left(E^{\prime}\right)$ and loss modulus $\left(E^{\prime \prime}\right)$ of the PP and PP-FS fibers in range $-125 / 100^{\circ} \mathrm{C}$ are reported in Figure $8 \mathrm{a}-8 \mathrm{c}$ for as-spun and drawn fibers. For $D R=1$ a marked rise in the storage moduli with the nanofiller content can be observed reaching the highest values for $\mathrm{AR} 805-2$ in the interval $-100^{\circ} \mathrm{C}$ up to $-30^{\circ} \mathrm{C}$ (Figure 8a). On the other hand, at temperatures higher than $0^{\circ} \mathrm{C}$, all the composites exhibit almost the same values of storage modulus. With the drawing process, the storage modulus increases over the whole temperature range used, which can be attributed to the chain orientation induced by drawing. For drawn fibers the highest improvement was observed for the compositions with $1 \mathrm{vol} \%$ at $D R=10$ (Figure $8 \mathrm{~b}$ ), and for $0.5 \mathrm{vol} \%$ of FS at $D R=15$ (Figure 8c). Decreasing storage modulus of the composites with higher nanofiller fractions could be attributed to the formation of nanofiller aggregates (as observed by TEM analysis), which reduces the filler effectivity. Similarly to the storage modulus $\left(E^{\prime}\right)$, loss modulus ( $\left.E^{\prime \prime}\right)$ of PP-AR805 composite fibers rises with the draw ratio and FS content (Figures 8a-8c). PP displays three relaxations (transitions, loss peaks) localized in the range of about $-80^{\circ} \mathrm{C}(\gamma), 10^{\circ} \mathrm{C}(\beta)$ and $100^{\circ} \mathrm{C}(\alpha)$, where $\beta$ is the dominant relaxation. In the crystalline polymers the $\alpha$ transition is commonly considered to be associated with the molecular motion within the crystalline regions, the $\beta$ transition corresponds to the glass transition of the amorphous regions, and the $\gamma$ transition is believed to be related to limited molecular motions of short chain sections in both amorphous regions and crystalline domains [31, 32]. As already mentioned, the intensity of the $\beta$ relaxation depends on various factors, such as crystalline fraction, orientation of the amorphous phase, and nanofiller fraction. For all as-spun fibers only one $\beta$ relaxation peak at around $5^{\circ} \mathrm{C}$ can be observed (Fig- 
ure 8a), whose position does not significantly change with varying nanoparticle content (from $6.2^{\circ} \mathrm{C}$ for as-spun PP down to $0.5^{\circ} \mathrm{C}$ for AR805$0.5)$. After drawing process, $T_{\beta}$ shifts to lower temperatures, from $6.2^{\circ} \mathrm{C}$ for neat $\mathrm{PP}$ to $-26.7^{\circ} \mathrm{C}$ for
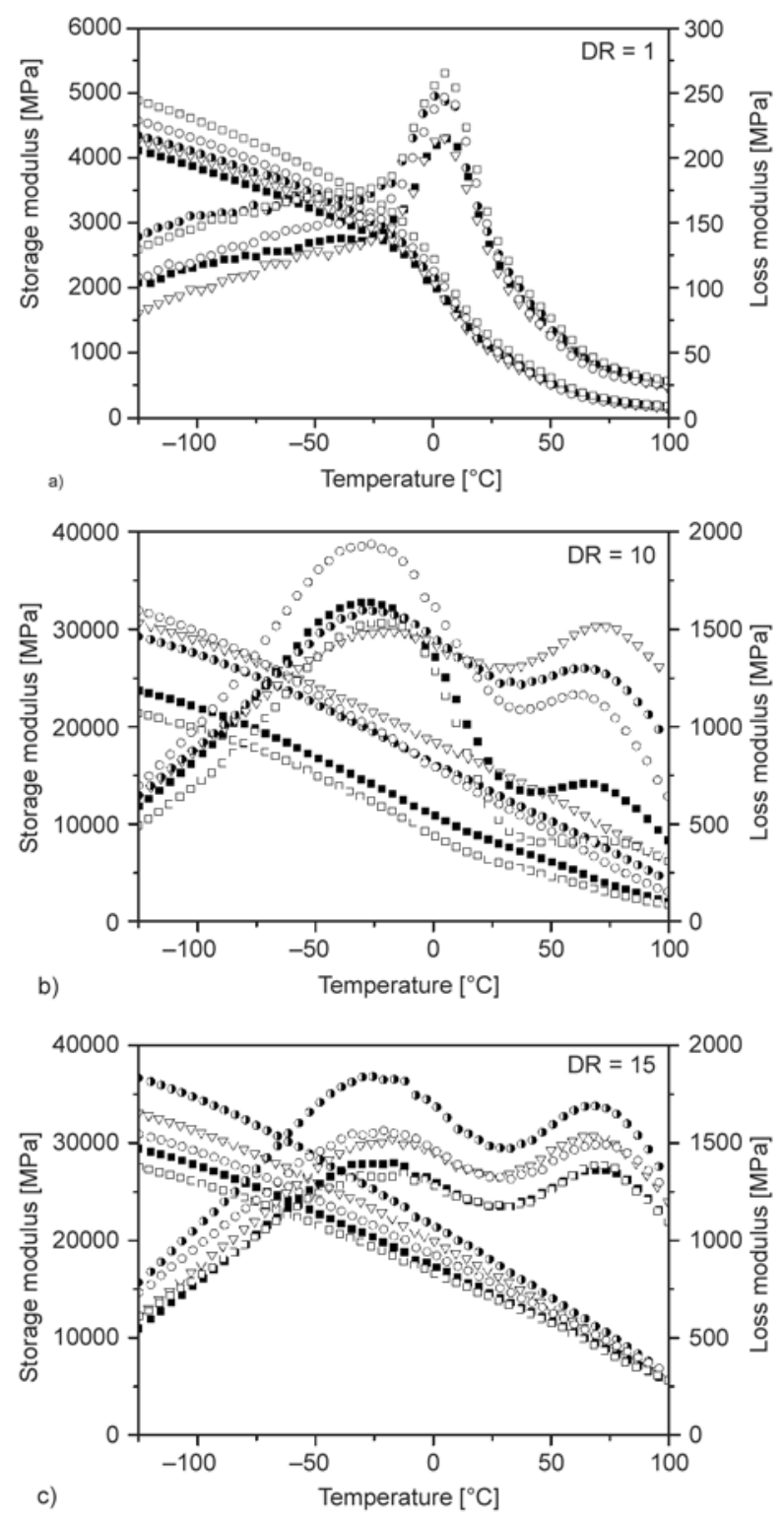

Figure 8. Storage modulus and loss modulus of neat PP (घ) and nanocomposite PP fibers with different fractions of fumed silica $(\nabla-0.25 \%, \odot-0.5 \%$, 。 $-1 \%$ and $\square-2 \%$ ) at selected draw ratios a) $D R=$ 1, b) $D R=10$ and c) $D R=15$
$D R=10$ and $\leq 23.4^{\circ} \mathrm{C}$ for $D R=15$. On the other hand, the nanofiller fraction slightly increases $T_{\beta}$, e.g. from $\leq 26.7^{\circ} \mathrm{C}$ for neat PP up to $-21^{\circ} \mathrm{C}$ for AR805-0.25 for $D R=10$ and from -23.4 up to $-21.6^{\circ} \mathrm{C}$ in case of composite AR805-0.25 with $D R=15$ (Table 5). It is commonly observed that after the nanofiller addition $T_{\beta}$ rises due to the adsorption of polymer chain on the surface of nanoparticles [33]. This effect is more pronounced after the drawing process which leads to more uniform distribution of the filler particles in the matrix. However, it is quite unusual the $T_{\beta}$ values decrease due to the drawing process. The effect was observed for drawn fibers $(D R \geq 10)$ and it can be attributed to the longitudinal defects developed during drawing that have been associated to a reduced density (and hence higher molecular mobility and lower $T_{\beta}$ ), in accordance to literature results. In fact, the higher the drawing, the longer the extension of the band defects, almost along all the fiber length $[34,35]$ at very high draw ratio.

As far as the $\alpha$ loss modulus peak is concerned, it can be seen that this relaxation is not observed for the asspun fibers, while for drawn materials a peak occurs at $69^{\circ} \mathrm{C}$. The magnitude of the $\alpha$ loss modulus peak (Table 5) increases proportionally to the draw ratio and/or filler fraction; the highest intensities were found for the compositions with $0.5 \mathrm{vol} \%$ of FS. This enhancement observed after drawing is probably related to the increase in the fraction of crystalline phase induced by the drawing process, as confirmed by DSC analysis (Figure 3). This $\alpha$ relaxation shifts to higher temperatures with increasing nanoparticle content and/or draw ratio. Owing to the drawing process, the peak is shifted from $68^{\circ} \mathrm{C}$ for neat $\mathrm{PP}$ at $D R=10$ to $71^{\circ} \mathrm{C}$ for $D R=15$ (Table 5). It is believed that higher crystalline continuity and/or dimensions achieved at high draw ratios hinder the underlying molecular motion so that the onset of the transition is shifted towards higher temperatures $[2,36]$.

Table 5. Temperature of the $\beta\left(T_{\beta}\right)$, and $\alpha\left(T_{\alpha}\right)$ loss peaks of the nanocomposite fibers with different fumed silica fraction and $D R$ (heating rate: $3^{\circ} \mathrm{C} / \mathrm{min}$; frequency: $1 \mathrm{~Hz}$ )

\begin{tabular}{|l|c|c|c|c|c|c|}
\hline \multirow{2}{*}{ Material } & \multicolumn{3}{|c|}{$\left.\mathbf{T}_{\boldsymbol{\beta}}{ }^{\circ} \mathbf{C}\right] / \mathbf{E}^{\prime \prime}$ peak $[\mathbf{M P a}]$} & \multicolumn{3}{c|}{$\mathbf{T}_{\boldsymbol{\alpha}}\left[{ }^{\circ} \mathbf{C}\right] / \mathbf{E}^{\prime \prime} \mathbf{p e a k}[\mathbf{M P a}]$} \\
\cline { 2 - 7 } & $\mathbf{D R}=\mathbf{1}$ & $\mathbf{D R}=\mathbf{1 0}$ & $\mathbf{D R}=\mathbf{1 5}$ & $\mathbf{D R}=\mathbf{1}$ & $\mathbf{D R}=\mathbf{1 0}$ & $\mathbf{D R}=\mathbf{1 5}$ \\
\hline PP & $6.2 / 215$ & $-26.7 / 1637$ & $-23.4 / 1393$ & - & $68.6 / 703$ & $71.4 / 1356$ \\
\hline AR805-0.25 & $4.9 / 216$ & $-20.7 / 1486$ & $-21.6 / 1503$ & - & $71.1 / 1516$ & $68.3 / 1533$ \\
\hline AR805-0.5 & $0.5 / 248$ & $-27.7 / 1600$ & $-25.5 / 1837$ & - & $64.5 / 1300$ & $68.6 / 1690$ \\
\hline AR805-1 & $4.9 / 247$ & $-26.3 / 1940$ & $-23.3 / 1560$ & - & $61.7 / 1163$ & $71.1 / 1490$ \\
\hline AR805-2 & $4.9 / 265$ & $-21.9 / 1530$ & $-22.0 / 1349$ & - & $68.6 / 423$ & $70.5 / 1390$ \\
\hline
\end{tabular}




\subsection{Creep test}

The creep tests were carried out in order to determine the deformation behavior of the materials under a constant load. In this experiment, a constant stress equal to $3 \mathrm{MPa}$ for $3600 \mathrm{~s}$ was applied to a fiber sample and the strain was monitored as a function of time. In Figures 9a-9c the creep compliance curves of the neat PP and nanofilled composites fibers at different draw ratio are reported. For as-spun fibers, the creep compliance of the nanocomposite fibers was higher than that of the neat PP. Interesting improvement of the creep resistance due to nanofiller intro-
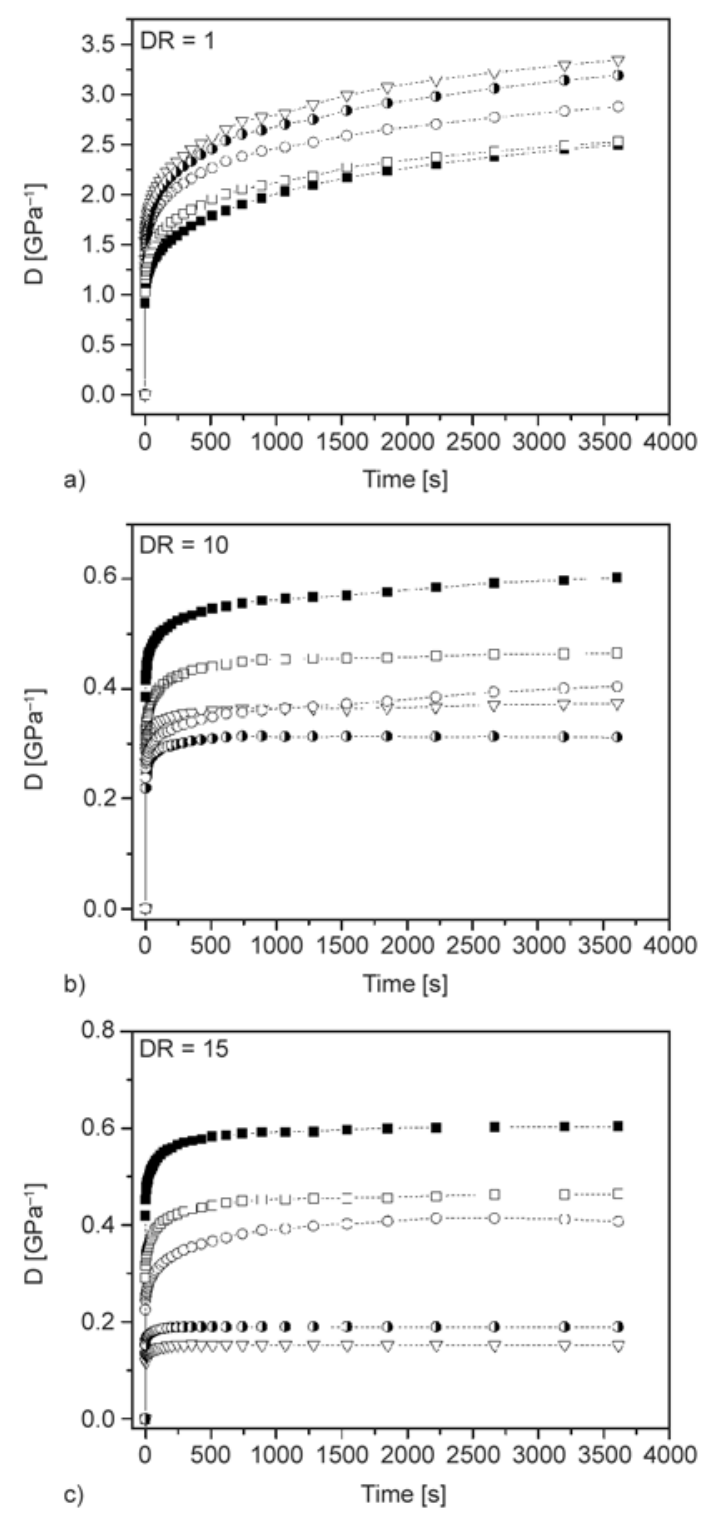

Figure 9. Tensile compliance of neat PP ( $\mathbf{\square})$ and nanocomposite PP fibers with different fractions of fumed silica $(\nabla-0.25 \%,-0.5 \%, \circ-1 \%$ and $\square-2 \%)$ as a function of time at selected draw ratios a) $D R=1$, b) $D R=10$ and c) $D R=15$ duction was observed after the drawing process. For all drawn fibers $(D R=10$ and 15$)$, a lower creep compliance was obtained as shown in Figure $9 \mathrm{~b}$ and $9 \mathrm{c}$, respectively. However, at a higher draw ratio $(D R=$ $15)$, the reduction of creep compliance was less significant for the composites with 1 and 2 vol\% of nanofiller than that observed for the composites with 0.25 and $0.5 \mathrm{vol} \%$ of FS. The creep compliance of fibers drawn 15 times was found to decrease in the following order: $\mathrm{PP}>805-2,805-1>805-0.5$, $805-0.25$. Lower creep resistance of the composites with high nanofiller fractions could tentatively be related to the reduced thickness of the interphase and to poorer adhesion caused by defects formation (for instance voids) and possible debonding. According to the interpretation of Siengchin and Karger-Kocsis [37], a well-dispersed reinforcement with good bonding to the matrix (i.e. well-developed interphase and reduced formation of voids) may improve the creep resistance of nanocomposites. We can conclude that the creep behavior of nanocomposite fibres is mainly governed by the filler distribution and adhesion, which can be improved in the course of the drawing process.

\subsection{Model of lamellae failure during drawing}

According to the model proposed by Chen et al. [38], the improvement of PP fracture toughness observed in fracture tests, both at low (static) and at high strain (dynamic), was interpreted according to mechanisms of polymer chains and crystalline modification in the damage zone, such as via lamellae transformation, break-up of lamellae, and defolding with voids formation.

On the basis of the analysis of thermo-mechanical properties and TEM photographs described in previous paragraphs, a model of the lamella reorganization during the fiber drawing process is proposed. Figure 10 shows a sketch where lamellae are held together by tie molecules and start to separate from one another upon initial drawing that occurs already during extrusion. The lamellae involved in this network deform and break-up by tilting and slippages and their separation is accompanied by microvoid formation. This plastic deformation via break-up and defolding of the lamellae triggers the polymorphic transformation which occurs in the course of recrystallization process. Moreover, this structure rebuilding is also associated with volume contraction (see the contribution of crystallinity in Table 2); since 


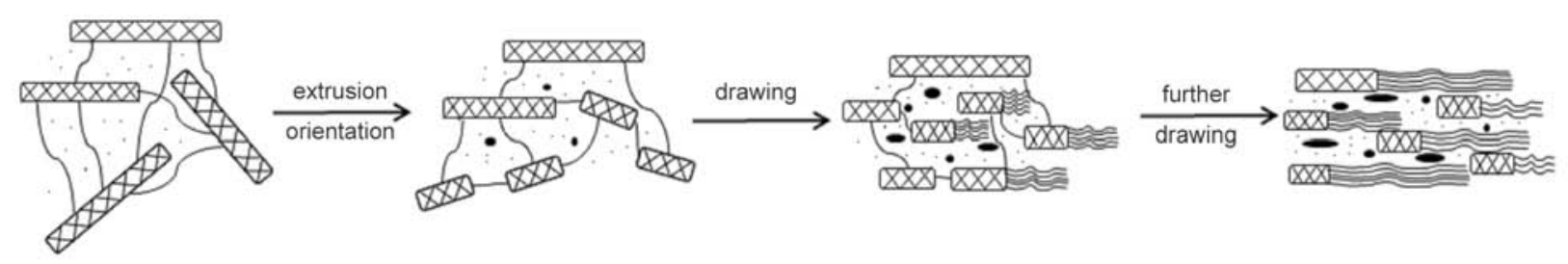

Figure 10. Scheme of the failure mode of the lamellae occurring during drawing process

the sample volume does not relax during the drawing process, the transition should amplify formation of microvoids. In the course of further drawing, the process of lamellae delamination and failure with the progressive chain orientation, and the voids formation becomes more intensive. In this latter critical step, the presence of some uniformly distributed nanoparticles, as in the case of $0.25-0.5 \mathrm{vol} \% \mathrm{FS}$, could promote a more regular voids formation and growth. The changes that occurred during the drawing process account - in term of this model - for enhancement of the mechanical properties of nanocomposite fibers, e.g. storage modulus, tensile strength, and creep resistance.

Better results obtained for the composites with low nanofiller content $(0.25-0.5$ vol\%) can primarily attributes to good nanofiller dispersion/distribution, and to the orientation of the filler nanoparticles during drawing and creeping test, where fumed silica seems also to play the role of regulating agent in voids formation.

\section{Conclusions}

PP-fumed silica Aerosil ${ }^{\circledR}$ R805 fibers were produced by a combined melt-extrusion and hot-drawing process (up to the draw ratio 15). The incorporation of fumed silica into the PP matrix leads to improvement of a wide range of mechanical properties, which is more effective at low filler fractions. Higher crystallinity content and crystallization temperature in the cooling step of as-spun composite fibers can be ascribed to nucleating role of dispersed fumed nanosilica. After drawing, fibers exhibited a significant increase in both melting temperature and crystallinity content.

DMTA evidenced the stiffening effect of silica which is magnified by drawing composite fibers to high draw ratios. Similarly enough, creep tests demonstrated a significant reduction of the creep compliance of all drawn fibers. The improvements in mechanical properties observed in nanocompos- ite fibers can mainly be attributed to a good dispersion of silica particles (observed by TEM) and to sufficient interfacial adhesion between matrix and filler. However, TEM micrographs revealed that the amount of nanoparticle agglomerates was proportional to the filler fraction in composites, but decreased with the fiber draw ratio.

The addition of low amounts of fumed silica (0.25$1 \mathrm{vol} \%$ ) was found optimal to improve the tensile mechanical properties. Tested samples exhibited a marked increase in elastic modulus and stress at break, whereas no significant variations of strain at break were observed. For example, PP fiber with $0.5 \mathrm{vol} \%$ of nanosilica showed - in comparison to the neat $\mathrm{PP}$ - higher values of the maximum attainable modulus (about $12.7 \mathrm{GPa}$ vs $9.6 \mathrm{GPa}$ ) and of the maximum attainable stress at break $(1.88 \mathrm{GPa}$ vs $1.49 \mathrm{GPa}$ ).

A failure model was proposed to interpret experimental data in terms of polymer chain orientation, re-crystallization of the amorphous regions, and void formation in the presence of fumed silica nanoparticles (up to $0.5-1$ vol\%), which are believed to have beneficial effects on mechanical properties of the prepared composites.

\section{Acknowledgements}

The authors thank to Evonik (Essen, Germany) for donating the fumed silica Areosi ${ }^{\circledR} \mathrm{R} 805$ used in this study. The authors are very indebted to Professor József Karger-Kocsis (Budapest University of Technology and Economics, Budapest) for his valuable comments. Electron microscopy at the Institute of Macromolecular Chemistry was supported through grant GACR P108/14-17921S.

\section{References}

[1] Harutun G. K.: Handbook of polypropylene and polypropylene composites. Marcel Dekker, New York (1999).

[2] Toshio K.: High-modulus and high-strength polypropylene fibers and films. in 'Polypropylene an a-z reference' (ed.: Karger-Kocsis J.) Kluwer Academic Publishers, Dordrecht, 295-300 (1999). 
[3] Wishman M., Hagler G. E.: Polypropylene fibers. in 'Handbook of fiber science and technology fiber chemistry' (eds.: Lewin P., Pearce E. M.) Marcel Dekker, New York, 371-497 (1985).

[4] Kearns J. C., Shambaugh R. L.: Polypropylene fibers reinforced with carbon nanotubes. Journal of Applied Polymer Science, 86, 2079-2084 (2002).

DOI: $10.1002 /$ app. 11160

[5] Kumar S., Doshi H., Srinivasarao M., Park J. O., Schiraldi D. A.: Fibers from polypropylene/nano carbon fiber composites. Polymer, 43, 1701-1703 (2002). DOI: 10.1016/S0032-3861(01)00744-3

[6] López Manchado M. A., Valentini L., Biagiotti J., Kenny J. M.: Thermal and mechanical properties of single-walled carbon nanotubes-polypropylene composites prepared by melt processing. Carbon, 43, 1499 1505 (2005).

DOI: 10.1016/j.carbon.2005.01.031

[7] Rangasamy L., Shim E., Pourdeyhimi B.: Structure and tensile properties of nanoclay-polypropylene fibers produced by melt spinning. Journal of Applied Polymer Science, 121, 410-419 (2011).

DOI: 10.1002/app.33619

[8] Joshi M., Shaw A., Butola B. S.: Studies on composite filaments from nanoclay reinforced polypropylene. Fibers and Polymers, 5, 59-67 (2004). DOI: $10.1007 / \mathrm{BF} 02875496$

[9] D’Amato M., Dorigato A., Fambri L., Pegoretti A.: High performance polyethylene nanocomposite fibers. Express Polymer Letters, 6, 954-964 (2012). DOI: $10.3144 /$ expresspolymlett.2012.101

[10] Zhang Y., Yu J., Zhou C., Chen L., Hu Z.: Preparation, morphology, and adhesive and mechanical properties of ultrahigh-molecular-weight polyethylene/ $\mathrm{SiO}_{2}$ nanocomposite fibers. Polymer Composites, 31, 684-690 (2010).

DOI: $10.1002 /$ pc. 20847

[11] Wu C. L., Zhang M. Q., Rong M. Z., Friedrich K.: Tensile performance improvement of low nanoparticles filled-polypropylene composites. Composites Science and Technology, 62, 1327-1340 (2002). DOI: 10.1016/S0266-3538(02)00079-9

[12] Rottstegge J., Qiao Y. K., Zhang X., Zhou Y., Xu D., Han C. C., Wang D.: Polymer nanocomposite powders and melt spun fibers filled with silica nanoparticles. Journal of Applied Polymer Science, 103, 218-227 (2007).

DOI: $10.1002 /$ app. 25162

[13] Srisawat N., Nithitanakul M., Srikulkit K.: Spinning of fibers from polypropylene/silica composite resins. Journal of Composite Materials, 46, 99-110 (2011). DOI: $10.1177 / 0021998311410477$

[14] Srisawat N., Nithitanakul M., Srikulkit K.: Characterizations of fibers produced from polypropylene/silica composite. Journal of Materials and Minerals, 19, 5358 (2009).
[15] Ikeda Y., Kohjiya S.: In situ formed silica particles in rubber vulcanizate by the sol-gel method. Polymer, 38, 4417-4423 (1997).

DOI: $10.1016 / \mathrm{S} 0032-3861(96) 01037-3$

[16] Barthel H., Rösch L., Weis J.: Fumed silica - Production, properties, and applications. in 'Organosilicon Chemistry Set: From Molecules to Materials’ (eds.: Auner N., Weis J.) Wiley, Weinheim, 761-778 (1996). DOI: 10.1002/9783527620777.ch91a

[17] Dorigato A., Sebastiani M., Pegoretti A., Fambri L.: Effect of silica nanoparticles on the mechanical performances of poly(lactic acid). Journal of Polymers and the Environment, 20, 713-725 (2012).

DOI: $10.1007 / \mathrm{s}$ 10924-012-0425-6

[18] Joshi M., Viswanathan V.: High-performance filaments from compatibilized polypropylene/clay nanocomposites. Journal of Applied Polymer Science, 102, 2164-2174 (2006).

DOI: $10.1002 /$ app. 24179

[19] Van Krevelen D. W.: Properties of polymers. Elsevier, Amsterdam (1990).

[20] Zhang M. Q., Rong M. Z., Ruan W. H.: Nanoparticles/polymer composites: Fabrication and mechanical properties. in 'Nano- and micro-mechanics of polymer blends and composites' (eds.: Karger-Kocsis J., Fakirov S.) Hanser, Munich, 91-140 (2009).

[21] Chiu C-W., Lin C-A., Hong P-D.: Melt-spinning and thermal stability behavior of $\mathrm{TiO}_{2}$ nanoparticle/polypropylene nanocomposite fibers. Journal of Polymer Research, 18, 367-372 (2011).

DOI: $10.1007 / \mathrm{s} 10965-010-9426-0$

[22] Lorenzi D., Sartori G., Ferrara G., Fambri L.: Spinnability of nanofilled polypropylene. Macromolecular Symposia, 301, 73-81 (2011). DOI: $10.1002 /$ masy.201150310

[23] Capaccio G., Crompton T. A., Ward I. M.: Ultra-high modulus polyethylene by high temperature drawing. Polymer, 17, 644-645 (1976). DOI: 10.1016/0032-3861(76)90288-3

[24] Fambri L., Dabrowska I., Pegoretti A., Ceccato R.: Melt spinning and drawing of polyethylene nanocomposite fibers with organically modified hydrotalcite. Journal of Applied Polymer Science, 131, 40277/140277/13 (2014).

DOI: 10.1002/app.40277

[25] Lee S. H., Youn J. R.: Properties of polypropylene/layered-silicate nanocomposites and melt-spun fibers. Journal of Applied Polymer Science, 109, 1221-1231 (2008). DOI: 10.1002/app.28222

[26] Kontou E., Niaounakis M.: Thermo-mechanical properties of $\mathrm{LLDPE} / \mathrm{SiO}_{2}$ nanocomposites. Polymer, 47, 1267-1280 (2006).

DOI: $10.1016 /$ j.polymer.2005.12.039 
[27] Dorigato A., D'Amato M., Pegoretti A.: Thermomechanical properties of high density polyethylene fumed silica nanocomposites: Effect of filler surface area and treatment. Journal of Polymer Research, 19, 9889/1-9889/11 (2012).

DOI: $10.1007 / \mathrm{s} 10965-012-9889-2$

[28] Dabrowska I., Fambri L., Pegoretti A., Ferrara G.: Organically modified hydrotalcite for compounding and spinning of polyethylene nanocomposites. Express Polymer Letters, 7, 936-949 (2013).

DOI: $10.3144 /$ expresspolymlett.2013.91

[29] Tomka J. G.: Textile fibres. in 'Comprehensive polymer science and supplements' (ed.: Allen G., Bevington J. C.) Pergamon, Amsterdam, Vol. 2, 487-510 (1989). DOI: $10.1016 / \mathrm{B} 978-0-08-096701-1.00051-3$

[30] Fambri L., Bragagna S., Migliaresi C.: Biodegradable fibers of poly-L, DL-lactide 70/30 produced by melt spinning. Macromolecular Symposia, 234, 20-25 (2006).

DOI: $10.1002 /$ masy.200650204

[31] Matsuoka S.: Relaxation phenomena in polymers. Hanser, Munich (1992).

[32] Boyd R. H.: Relaxation processes in crystalline polymers: Molecular interpretation - A review. Polymer, 26, 1123-1133 (1985).

DOI: 10.1016/0032-3861(85)90240-X

[33] Vladimirov V., Betchev C., Vassiliou A., Papageorgiou G., Bikiaris D.: Dynamic mechanical and morphological studies of isotactic polypropylene/fumed silica nanocomposites with enhanced gas barrier properties. Composites Science and Technology, 66, 2935-2944 (2006).

DOI: $10.1016 /$ j.compscitech.2006.02.010
[34] Abo El Maaty M. I., Bassett D. C., Olley R. H., Dobb M. G., Tomka J. G., Wang I-C.: On the formation of defects in drawn polypropylene fibres. Polymer, 37, 213-218 (1996). DOI: 10.1016/0032-3861(96)81090-1

[35] Amornsakchai T., Olley R. H., Bassett D. C., Al-Hussein M. O. M., Unwin A. P., Ward I. M.: On the influence of initial morphology on the internal structure of highly drawn polyethylene. Polymer, 41, 8291-8298 (2000). DOI: $10.1016 / \mathrm{S} 0032-3861(00) 00144-0$

[36] Alcock B., Cabrera N. O., Barkoula N-M., Reynolds C. T., Govaert L. E., Peijs T.: The effect of temperature and strain rate on the mechanical properties of highly oriented polypropylene tapes and all-polypropylene composites. Composites Science and Technology, 67, 2061-2070 (2007).

DOI: 10.1016/j.compscitech.2006.11.012

[37] Siengchin S., Karger-Kocsis J.: Creep behavior of polystyrene/fluorohectorite micro- and nanocomposites. Macromolecular Rapid Communications, 27, 2090-2094 (2006).

DOI: $10.1002 /$ marc. 200600539

[38] Chen H. B., Karger-Kocsis J., Wu J. S., Varga J.: Fracture toughness of $\alpha$ - and $\beta$-phase polypropylene homopolymers and random- and block-copolymers. Polymer, 43, 6505-6514 (2002). DOI: $10.1016 / \mathrm{S} 0032-3861(02) 00590-6$ 